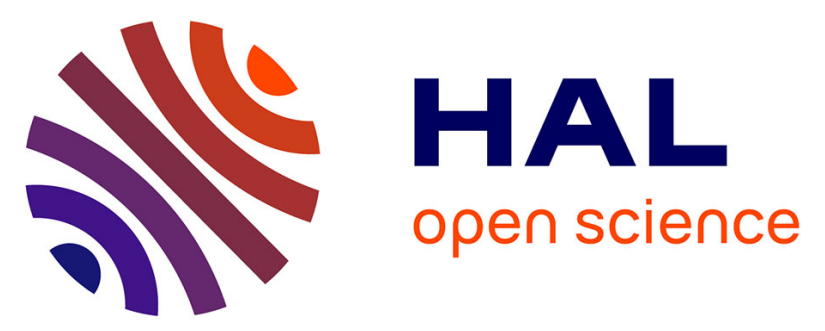

\title{
Effect of a Post-Fatigue Damage on the Residual Dynamic Behavior of Advanced-SMC Composites
}

Mohammadali Shirinbayan, Joseph Fitoussi, Fodil Meraghni, S. Farzaneh, Benjamin Surowiec, Abbas Tcharkhtchi

\section{- To cite this version:}

Mohammadali Shirinbayan, Joseph Fitoussi, Fodil Meraghni, S. Farzaneh, Benjamin Surowiec, et al.. Effect of a Post-Fatigue Damage on the Residual Dynamic Behavior of Advanced-SMC Composites. Applied Composite Materials, 2019, pp.1-19. 10.1007/s10443-019-09782-6 . hal-02318740

\author{
HAL Id: hal-02318740 \\ https://hal.science/hal-02318740
}

Submitted on 17 Oct 2019

HAL is a multi-disciplinary open access archive for the deposit and dissemination of scientific research documents, whether they are published or not. The documents may come from teaching and research institutions in France or abroad, or from public or private research centers.
L'archive ouverte pluridisciplinaire HAL, est destinée au dépôt et à la diffusion de documents scientifiques de niveau recherche, publiés ou non, émanant des établissements d'enseignement et de recherche français ou étrangers, des laboratoires publics ou privés. 


\title{
Effect of a Post-Fatigue Damage on the Residual Dynamic Behavior of Advanced-SMC Composites
}

\author{
M. Shirinbayan ${ }^{1}$ - J. Fitoussi ${ }^{1} \cdot$ F. Meraghni ${ }^{2} \cdot$ S. Farzaneh ${ }^{3} \cdot$ B. Surowiec ${ }^{4}$. $^{-}$ \\ A. Tcharkhtchi ${ }^{1}$
}

\begin{abstract}
The purpose of this article is to investigate the effect of an initial pre-damage induced by a fatigue loading on the tensile dynamic behavior of Advanced Sheet Molding Compounds (A$\mathrm{SMC}$ ). Tension-tension fatigue preloading at a frequency of $30 \mathrm{~Hz}$ is performed at various applied stress levels prior to subject the A-SMC specimens to tensile tests at different strain rates, namely: $10^{-3} \mathrm{~s}^{-1}$ (quasi-static), $1 \mathrm{~s}^{-1}$ and $60 \mathrm{~s}^{-1}$. The developed experimental approach provided significant findings in terms of residual behavior and damage accumulation in relation to the applied pre-fatigue loading conditions. Indeed, it has been shown that the overall quasi-static and the dynamic responses are strongly affected by the level of fatigue number of cycles reached prior to applying the high strain loading. The effect of fatigue predamage is found also strongly strain-rate dependent. Experimental results showed that the damage threshold in terms of stress and strain increased with strain rate. However, for a given strain-rate the damage stress threshold depends on the number of cycles applied during the fatigue preloading.
\end{abstract}

Keywords Fatigue $\cdot$ Pre-damage $\cdot$ Dynamic $\cdot$ Residual behavior 


\section{Introduction}

In order to protect automobile passengers from injury during a crash, car crash experiments should be performed to simulate the actual accident [1-5]. To obey this matter an optimum combination of body structure with material and also an exact evaluation of fatigue behavior and dynamic response of the constitutive material is highly required [4, 5]. In fact, one can note that basically, the automotive component is not always at an undamaged state. Indeed, in many applications, especially the automotive structural components, constitutive materials are subjected to vibration or oscillation forces [6-9] inducing a fatigue pre-damage accumulation prior to undergo the service loading. Thus, for a precise prediction of the dynamic response and the related energy absorption, the study of the material behavior exhibiting a fatigue pre-damage by performing fatigue tests prior high strain rate loading is of high importance.

An understanding of fatigue behavior is important for any material that experiences repeated loading during service [6-9]. Fatigue response of composites is usually characterized by an S-N curve, also known as a Wöhler curve $[5,6]$. It can be presented as a curve giving the value of cyclic stress amplitude, $\sigma_{\max }$, versus the number of cycles to failure, N. Fiber orientations, applied stresses, temperature, frequency, and self-heating effects are main parameters to reliably estimate the cyclic behavior of the materials [10-12]. Many authors [7] have indicated that augmentation of the fatigue stress, $\sigma_{\max }$, leads to a stiffness reduction rate and shorter fatigue life. The undamaged material constitution is defined in terms of the material elastic modulus, mass density, and yield stress.

The classical approach to characterize the crash events is by using high strain rate tensile tests. Mechanical response of materials is sensitive to the rate at which they are loaded. [13-18]. Therefore, for the effective use of materials, their response under various strain rates should be clearly understood.

The question asked in this paper can be formulated as follows: What is the effect of fatigue stress on the residual dynamic behavior of A-SMC material? Answering this question requires defining the scale of the analysis to be proposed. Indeed, one can be interested in this coupling at different scales: macroscopic, microscopic or even nanometric scales. From the macroscopic point of view, we must consider the evolution of the post-fatigue dynamic response, which would allow us to equip ourselves with more representative behavioral laws for the crash dimensioning of real automotive structures. Indeed, the automotive structures are hitherto always dimensioned on the basis of mechanical characterizations made on materials which have not undergone any stress. However, most automobile structures are subjected to stresses of fatigue type before they undergo a crash. On a finer scale - local phenomena of deformation and damage are at the origin of the macroscopic responses. Are there specific phenomena during fatigue which would modify the response under a rapid solicitation? For example, in the case of thermoplastic matrix composite materials, it has been shown that repeated stresses may produce a progressive accumulation of plastic deformation and/or specific damage phenomena at the interfaces/interphase fiber-matrix. Finally, on an even finer scale, one can also ask the question of the effect of modifications of the macromolecular architecture in the fatigue test.

One can note that mechanical behavior during subsequent loading appears to be only slightly affected by the type of initial loading mode. Two sequences of tension/fatigue and fatigue/tension tests were performed on copper poly-crystal sheet by Jia et al. [19]. The strain rate for the tension tests was in the domain of quasi-static tensile tests, while the fatigue tests were performed under constant plastic strain amplitude control. In the case of fatigue/tension, it was found that the fatigue stage had a significant influence on the subsequent yield and flow 
behavior in tension. For tension/fatigue, the strain amount of preloading in quasi-static tensile test clearly affected the initial cyclic loading, while it had almost no effect on the saturation stress of following fatigue test.

An impact fatigue study on $35 \%$ jute/vinyl-ester composites [20] showed that the defect concentration played an important role in the fatigue behavior of the composites under impact loading.

Epaarachchi [21] investigated the effects of static-fatigue interaction on tension-tension fatigue life of glass fiber reinforced plastic (GFRP) composites. Static-fatigue interaction results showed a considerable effect on fatigue behavior at intermediate and lower applied stress due to longer exposure to applied loads.

What is the impact of these different types of evolution on the residual behavior under rapid solicitation? It is clear that this theme could be the subject of several years of research. In this work, we will only propose a comparison of the post-fatigue dynamic properties with that of the same virgin material. As mentioned above, this comparison is necessary in order to ensure a realistic dimensioning.

SMCs and A-SMCs are high strength glass reinforced thermoset molding materials processed by thermo-compression [22, 23], which are ideal for large structural automotive components because of their high strength-to-weight ratio [13]. Vinyl-esters resins used for new Advanced SMCs (A-SMC) exhibit many desirable features, including mechanical properties comparable to those of epoxy. It was reported that fiber-matrix interface debonding, matrix microcracking, fiber pull-out and breakage, delamination and pseudo-delamination were some of the main damage mechanisms observed under fatigue tests for SMC composites. Tensile curves obtained for A-SMC samples showed clearly that the overall behavior is highly loadrate dependent. Indeed, under rapid tensile load, A-SMC composites exhibit typically a nonlinear response. Measuring Young's modulus and material mechanical characteristics such as damage thresholds corresponding to the first non-linearity $\left(\sigma_{\text {threshold }} ; \varepsilon_{\text {threshold }}\right)$ and ultimate stress and strain $\left(\sigma_{\text {ultimate }} ; \varepsilon_{\text {ultimate }}\right)$ as a function of strain rate have been developed for glass fiber reinforced composites, especially A-SMC composites [13-18].

So far no sequential loading study, which is highly related to technical applications, has been performed on SMC composites with fatigue as one of the loading modes and high strain rate as the second loading mode. This test is very remarkable to determine the mechanical characterization of the Advanced SMC (A-SMC).

Randomly Oriented A-SMC (RO-A-SMC) plates have been provided by Plastic Omnium Auto Exterior. In this paper, an experimental procedure is carried out to investigate the effect of strain rate on the overall behavior of pre-damage RO-A-SMC under fatigue tests. In the coupled loading of fatigue crash, the fatigue procedures with quasi-static and high loading amplitudes perform until defined cycles before failure of samples at the frequency of $30 \mathrm{~Hz}$. One can note that this value of frequency is equal to vehicle vibration during usage. After the fatigue stage, the damaged composite is subjected to quasi-static and high strain rate tensile test to simulate crash events.

After a microstructure presentation of A-SMC composite, the fatigue procedures in certain amplitudes and until defined cycles without failure of samples were presented in the preliminary characterization. All cyclic tests were performed at the frequency equal to $30 \mathrm{~Hz}$. After performing the fatigue tests until certain cycles, the tensile tests by varying the staining rate from the quasi-static to $60 \mathrm{~s}^{-1}$ were applied. The results of material characteristics, namely Young's modulus $(\mathrm{E})$; damage thresholds corresponding to the first non-linearity ( $\sigma_{\text {threshold }}$; $\left.\varepsilon_{\text {threshold }}\right)$ and ultimate stress and strain $\left(\sigma_{\text {ultimate }} ; \varepsilon_{\text {ultimate }}\right)$ were discussed. 


\section{Material Description and Methods}

\subsection{Advanced Sheet Molding Compound (A-SMC) Composite}

Advanced Sheet Molding Compound (A-SMC) composite consists of a vinyl-ester matrix with a high content of glass fibers ( $50 \%$ in mass corresponding to $38.5 \%$ in volume, $25 \mathrm{~mm}$ length). A-SMC as a thermoset material is a serious candidate for structural parts in the automotive industry. The process of manufacturing has been discussed in a previous paper [13]. The low process time is mandatory in the automotive industry due to the high production rhythm. The composition of A-SMC is shown in Table 1. In this study, Randomly Oriented (RO) plates of A-SMC composite have been provided by Plastic Omnium Auto Exterior.

\subsection{Methods}

\subsubsection{Characterization Methods}

X-Ray Micro-Tomography It allowed a three-dimensional visualization of A-SMC. EasyTom nano setup, which comprises an X-Ray source, a rotating table, and an X-ray detector, was used. The studied sample $\left(1 \times 1 \times 3 \mathrm{~cm}^{3}\right)$ was placed between the X-ray beam and the camera detector. The principle of operation of the microstructure analysis by X-ray micro-tomography is widely described in [24].

Thermo-Mechanical Properties In order to measure the main transitions temperatures due to molecular mobility as a function of temperature, DMTA tests have been performed on RO-ASMC samples at room temperature using DMA Q800 instrument, from TA Company. The tests have been realized at the following condition: alternating bending configuration; temperature range from $-100{ }^{\circ} \mathrm{C}$ to $250{ }^{\circ} \mathrm{C}$; frequency $1 \mathrm{~Hz}$; temperature rate $2{ }^{\circ} \mathrm{C} / \mathrm{min}$.

\subsubsection{Fatigue Tests}

Tension-tension fatigue tests have been performed at the different applied maximum stress on MTS 830 hydraulic fatigue machine. The minimum applied stress is always chosen to be equal to $10 \%$ of the maximum applied stress. In this paper, the results of experiments performed at the frequency of $30 \mathrm{~Hz}$ are presented. In order to measure precisely the stiffness reduction due to the first loading stage, each fatigue test is preceded by a quasi-static tensile loadingunloading-reloading stage.

Table 1 A-SMC composition

Product nature

Glass fibers

Vinyl-ester resin

Filler

Other products
Composition (content in mass percent)

$2 \%$ 
During cyclic loading, the temperature rise (due to self-heating) has been measured using an infrared camera (Raynger-MX4) in the specific area (maximum temperature). The evolution of Young's modulus is also determined.

\subsubsection{Tensile Tests}

Quasi-Static Tensile Tests Quasi-static tensile tests by the velocity of $2 \mathrm{~mm} / \mathrm{min}$ have been performed with MTS 830 hydraulic machine.

High-Speed Tensile Tests High-speed tensile tests have been performed upon a servohydraulic test machine. As specified by the manufacturer (Schenk Hydropuls VHS 5020), the test machine can reach a crosshead speed range from $10^{-4} \mathrm{~m} / \mathrm{s}$ (quasi-static) to $20 \mathrm{~m} / \mathrm{s}$. Moreover, the load level is measured by a piezoelectric crystal load cell having a capacity of a $50 \mathrm{kN}$. High-strain rate tensile tests were conducted at different strain-rates until the composite specimen total failure. The test machine is equipped with a launching system. The specimen is positioned between the load cell (upper extremity) and the moving device (lower extremity) as sketched in Fig. 1. A contactless technique [13] was used to measure the local deformation using high speed camera (FASTCAM-APX RS).

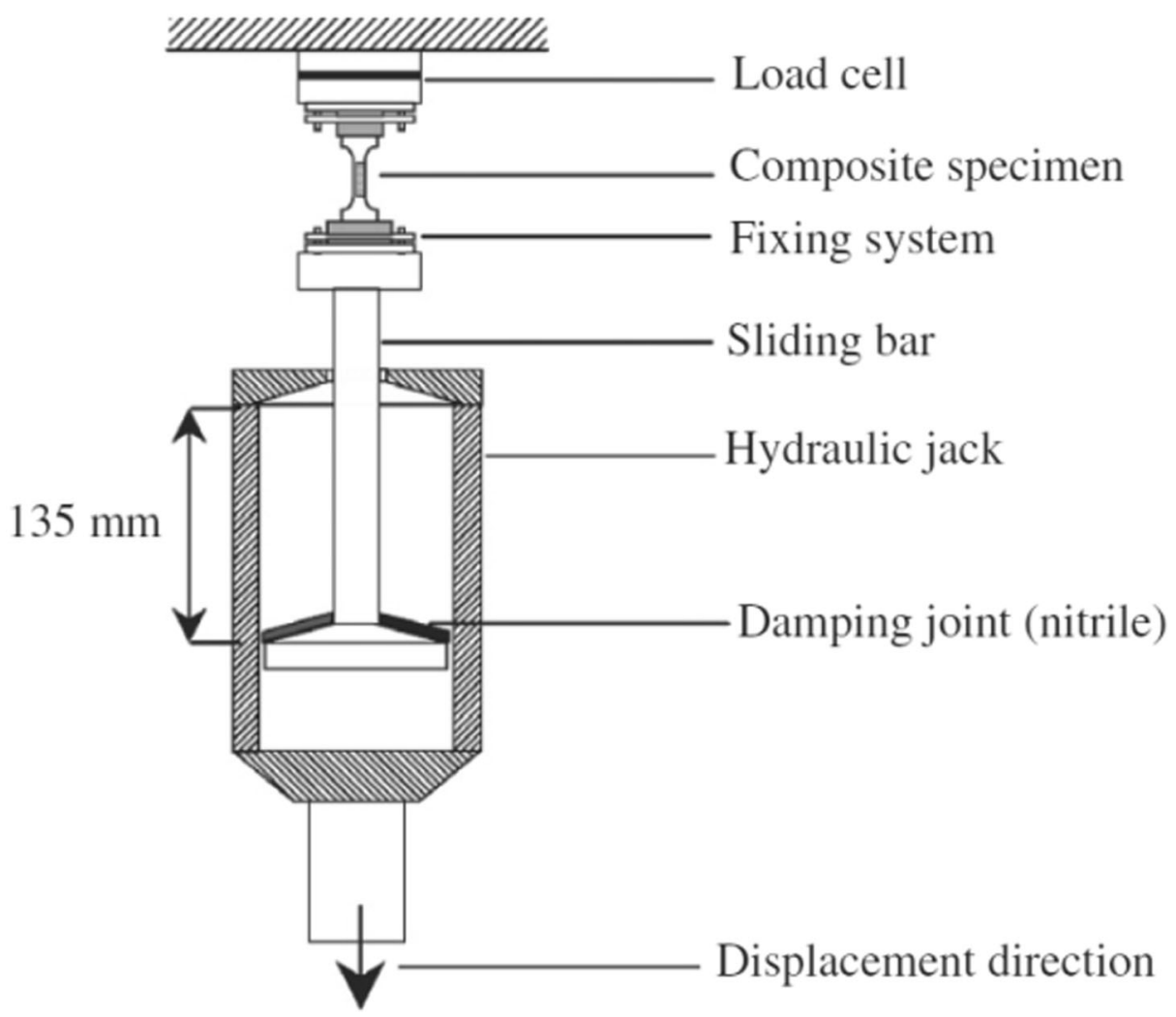

Fig. 1 Experimental device used for high-speed tensile tests 


\subsubsection{Specimen Geometry}

In a previous study [13], on the basis of FE simulations and assuming that the specimen behaves like an elastic anisotropic solid, a recursive optimization procedure results in the determination of optimal geometrical parameters for high speed tensile tests: $\mathrm{L}_{1}, \mathrm{~L}_{2}, \mathrm{~L}_{3}$ and $\mathrm{R}$ (Fig. 2). These parameters are optimized in such a way of reducing the stress wave effects in the overall response and of generating homogeneous stress/strain field during high strain rate tensile tests. The experimental coupled loading of fatigue crash was performed on the same geometry of the sample.

\section{Experimental Results and Discussion}

\subsection{Microscopic Characterization}

For three-dimensional visualization of A-SMC composite (Fig. 3), X-ray tomography technique was used. Actually, it can be observed not only microstructures of the skin, but also those of the shell and core. Indeed, fibers are initially randomly oriented before compression molding. The complete characterizations of A-SMC composite provided by Plastic Omnium Auto Exterior have been presented in the previous paper [13].

\subsection{Thermo-Mechanical Properties}

In order to measure the main transitions temperatures due to molecular mobility as a function of temperature, DMTA tests have been performed on RO-A-SMC samples as described in paragraph 2.2.1. Figure 4 shows the typical evolution of the storage modulus and the loss modulus versus temperature.

A-SMCs present a glass transition lying between 60 and $200{ }^{\circ} \mathrm{C}$. It can be assumed that this transition temperature is about $130^{\circ} \mathrm{C}$. Moreover, it can be assumed that the temperature range from $25{ }^{\circ} \mathrm{C}$ to $75{ }^{\circ} \mathrm{C}$ corresponds to the $\beta$-transition related in amorphous polymers to a ductile-brittle transition. In this zone, sufficient thermal agitation allows the activation of the movement of the radicals located at the periphery of the carbon chain. This transition can be considered as centered around $45^{\circ} \mathrm{C}$.

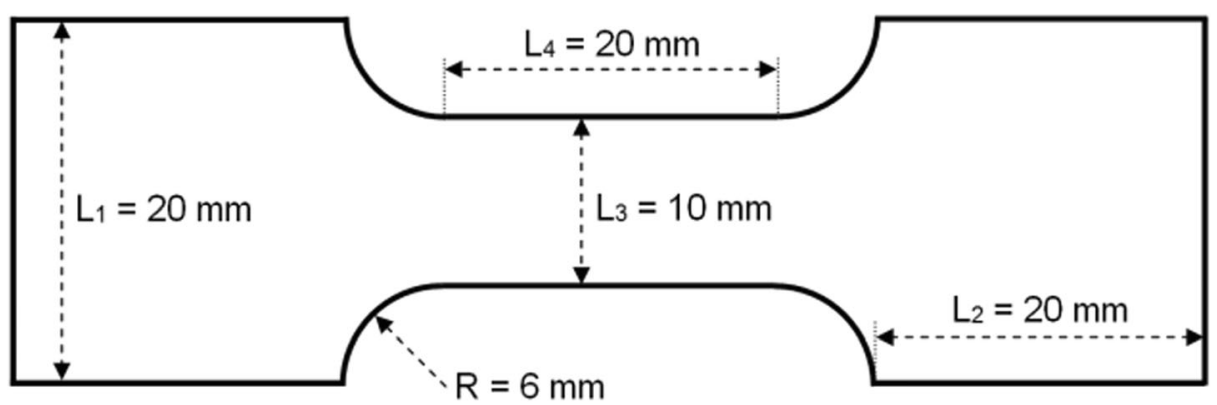

Fig. 2 Obtained specimen dimension from optimization procedure results 
Fig. 3 Three-dimensional visualization of A-SMC composite

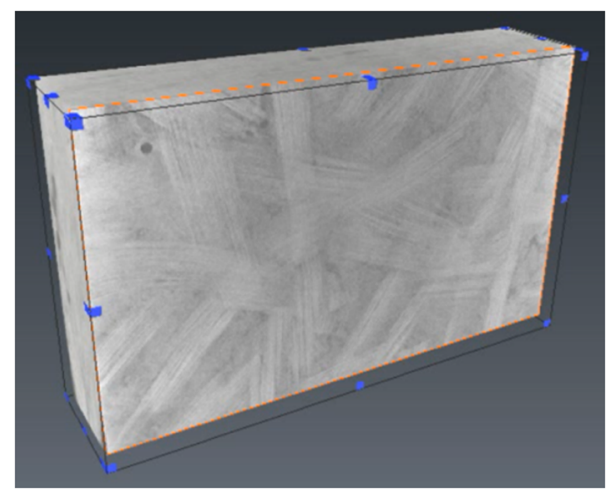

\subsection{Fatigue Behavior Analysis}

\subsubsection{Wöhler Curve and Self-Heating Phenomenon}

Figure 5(a) depicts the Wöhler curve of RO-A-SMC samples at the frequency of $30 \mathrm{~Hz}$. This figure demonstrates a linear logarithmic for the loading amplitudes varying from $0.45 \sigma_{\mathrm{r}}$ to $0.62 \sigma_{\mathrm{r}}$. One can observe that the Wöhler curve starts deviating for the lowest loading amplitudes. A variation of the applied stress from $0.45 \sigma_{\mathrm{r}}$ to $0.38 \sigma_{\mathrm{r}}$ (variation of $15 \%$ ) leads to 20 times higher fatigue lifetime (resp. $10^{5}$ cycles and $2 \times 10^{6}$ cycles).

Figure 5(b) illustrates the variation of temperature during fatigue tests at different amplitudes $(\mathrm{f}=30 \mathrm{~Hz})$. One can observe no significant temperature change before 200 cycles. For fatigue tests performed at $0.62 \sigma_{\mathrm{r}}$, the temperature increases rapidly from room temperature to $60{ }^{\circ} \mathrm{C}$ up to 2000 cycles while temperature variation does not exceed $10{ }^{\circ} \mathrm{C}$ for fatigue tests of $0.38 \sigma_{\mathrm{r}}$. One can note that the self-heating phenomenon depends directly on the viscoelastic behavior of the polymer. Increasing applied loading amplitude leads to more self-heating and matrix viscosity decreases [13, 25-26-27]. Therefore, fatigue conditions with applied stresses of $0.38 \sigma_{\mathrm{r}}, 0.45 \sigma_{\mathrm{r}}$ and $0.55 \sigma_{\mathrm{r}}$ were chosen until a defined number of cycles before failure of

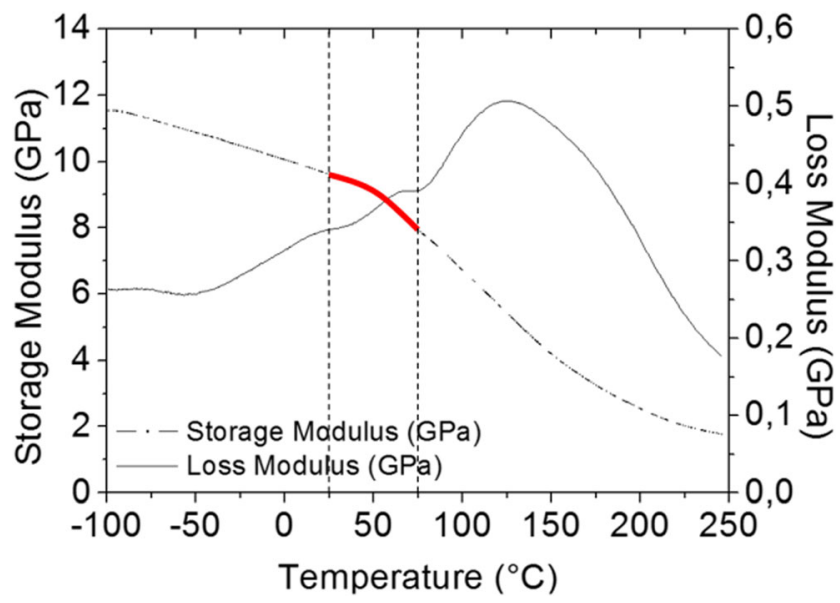

Fig. 4 DMTA test performed on RO-A-SMC 

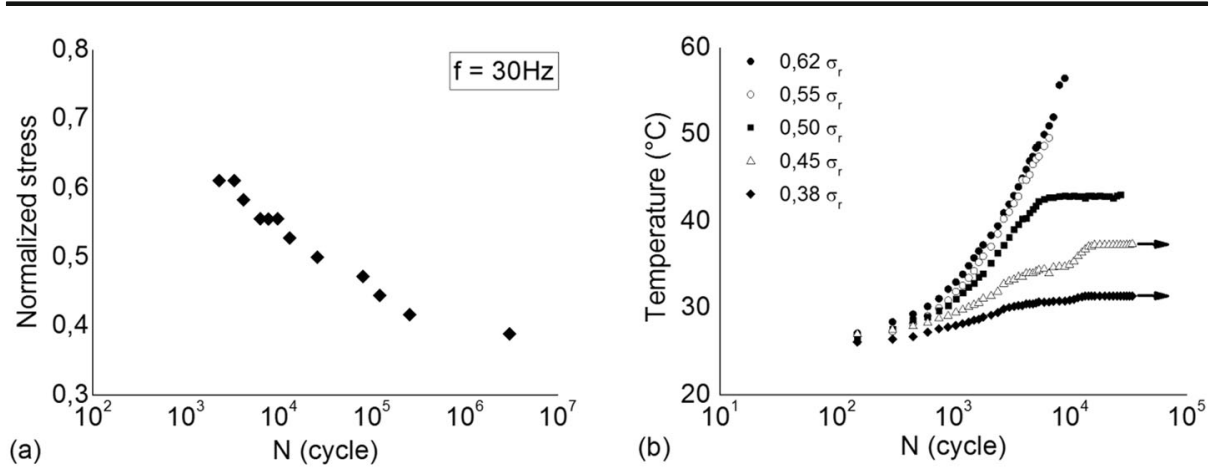

Fig. 5 a Normalized Wöhler curve at frequency of $30 \mathrm{~Hz}$, (b) Temperature variation at different amplitudes and frequency of $30 \mathrm{~Hz}$ (Normalized value = current value / average ultimate stress value $\left(\sigma_{\mathrm{r}}\right)$ obtained for quasi-static tensile tests performed on RO-A-SMC)

samples at the frequency of $30 \mathrm{~Hz}$. One can note that these fatigue conditions can have a significant effect on temperature rise which reaches the $\beta$-transition domain. In paragraph 3.4.1., this aspect is addressed in the analysis of the fatigue loss of stiffness.

\subsection{Analysis Methodology of Fatigue Damage Effect on Residual Dynamic Behavior}

In order to demonstrate the specific effect of fatigue on the residual dynamic behavior of ASMC composites, we need to define a reference state to which post-fatigue dynamic behavior should be compared. Since it has been demonstrated that damage is the main non-linear deformation mode in A-SMC composites, it is possible to define the residual stiffness, E, as an indicator of damage. Therefore, one can choose the stiffness of the non-damaged material, $\mathrm{E}_{0}$, as a reference value.

\subsubsection{Phenomenological Basic Considerations about Damage}

For an elastic damageable material such as A-SMC, one can consider the phenomenological point of view by analyzing the evolution of the relative stiffness, $\mathrm{E} / \mathrm{E}_{0}$. Since this parameter evolves for all types of loadings (fatigue, quasi-static and dynamic monotonic), it can be chosen as a damage indicator.

Consider a quasi-static loading-unloading test with the progressive increase of the maximum stress (Fig. 6). The envelope of the whole stress-strain curve should follow that of the monotonic tensile curve obtained under the same strain rate condition. Consider that the first loading-unloading stage is applied until a maximum value $\sigma_{1}$, higher than the damage threshold, $\sigma_{0}$. At the end of the loading stage, a population of micro-cracks is created at the local scale defining a damaged state which is related to a certain reduction of Young's modulus, $\mathrm{E} / \mathrm{E}_{0}$. We consider that unloading stages do not modify the local damage state. During the second loading stage (first reloading until $\sigma_{2}$ ), a new value of the apparent threshold stress (non-linearity) will be observed close to $\sigma_{1}$ (see Fig. 6). Thus, for a given strain rate, the non-linearity threshold will always approach a value close to the maximum stress previously reached. Moreover, failure should occur during the last reloading stage when reaching the ultimate stress observed for the monotonic tensile test until failure (Fig. 6). This basic analysis of damage behavior shows that a given damage state can be determined by two parameters: the residual stiffness and the associated damage threshold stress. 


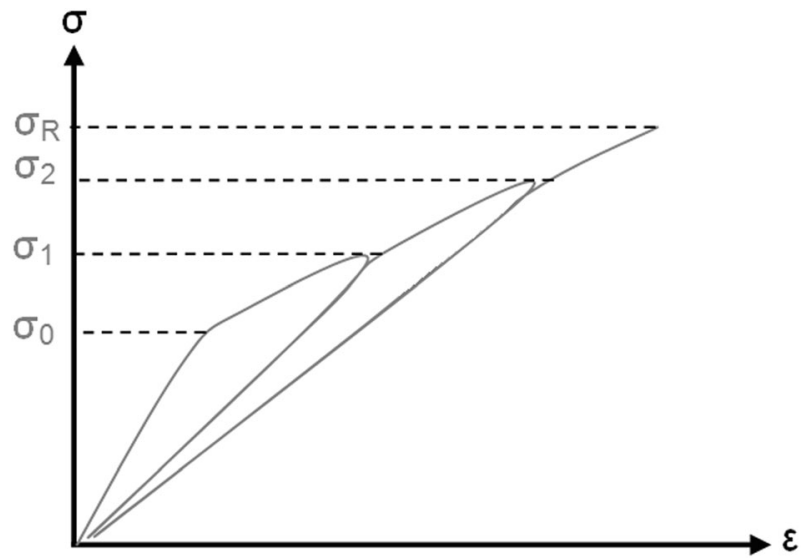

Fig. 6 Evolution of the apparent damage threshold during a tensile test

\subsubsection{Definition of a Reference Damage Threshold-Strain Rate Curve for a Given Damage State}

Let us now consider tensile curves at different strain rates as well as a given damaged state of the material characterized by a modulus $\mathrm{E}$ lower than the modulus of the virgin material $\mathrm{E}_{0}$ (Fig. 7a). For each value of strain rate, this specific damage state is associated with a specific value of the damage threshold (as discussed above). Therefore, the evolution of the damage threshold can be plotted as a function of the strain rate by construction as in Fig. 7. This evolution can be considered to be a reference curve for the considered damage state (defined by $\left.\mathrm{E} / \mathrm{E}_{0}\right)$.

It is, therefore, possible to define a reference curve per state of considered damage state describing the evolution of the threshold stress as a function of the strain rate.

\subsubsection{Definition of a Deviation Parameter}

Moreover, each considered macroscopic damage state (defined by $\mathrm{E}$ or $\mathrm{E} / \mathrm{E}_{0}$ ) can also be reached by an interrupted fatigue loading (Figs. 8). Consider several specimens submitted to fatigue loading until the considered damaged state $\left.\mathrm{E} / \mathrm{E}_{0}\right)$ is reached. These equivalent damaged

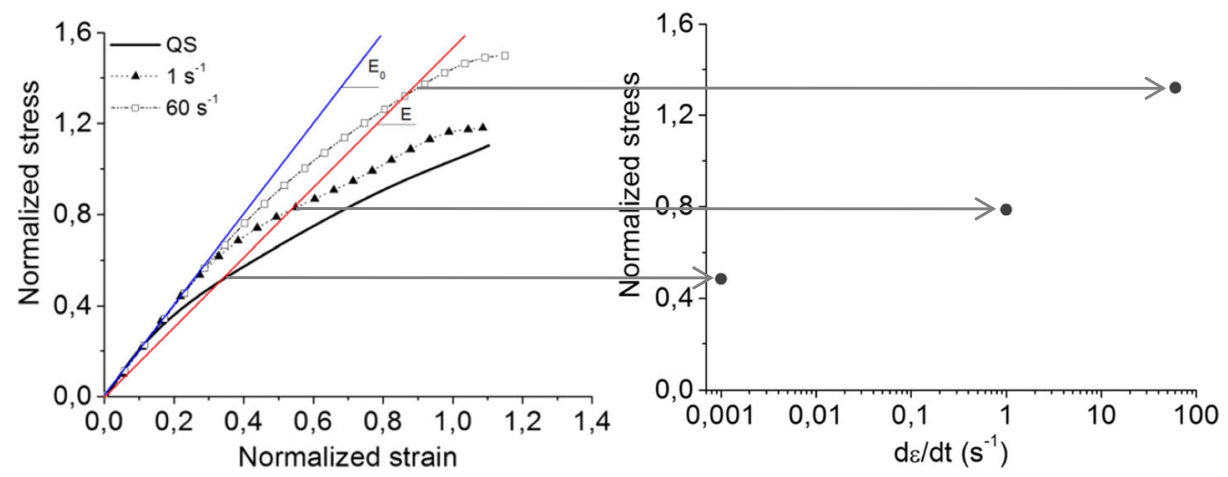

Fig. 7 Evolution of the apparent damage threshold as a function of the strain ratefor a given damage state 

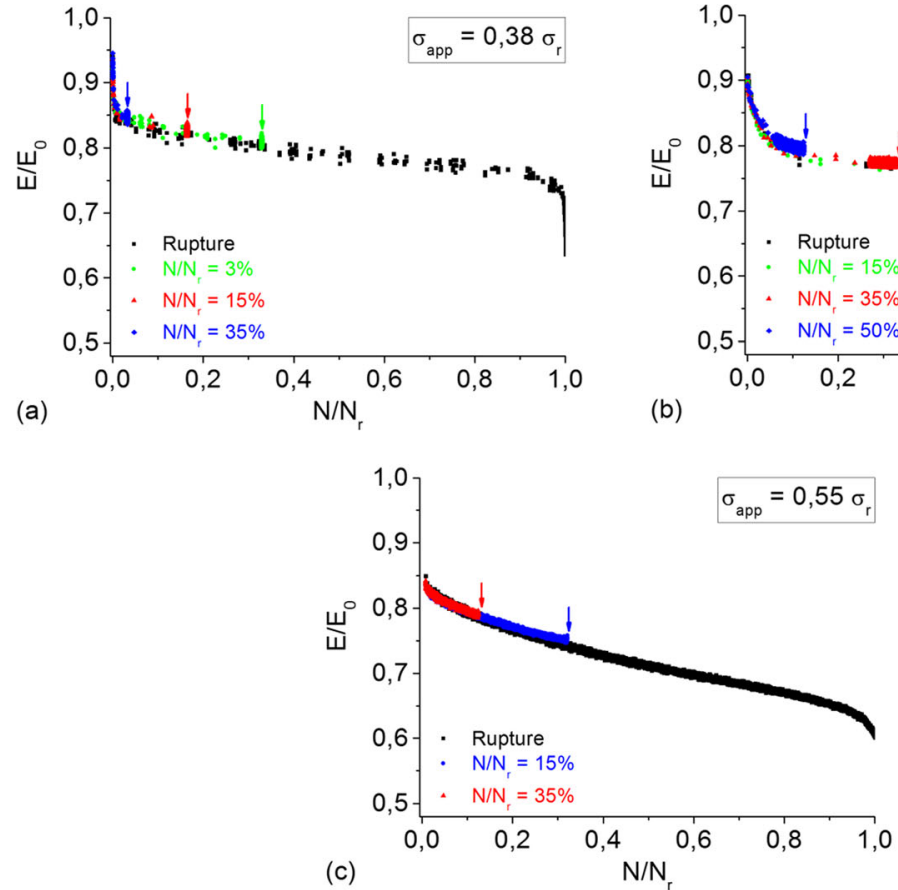

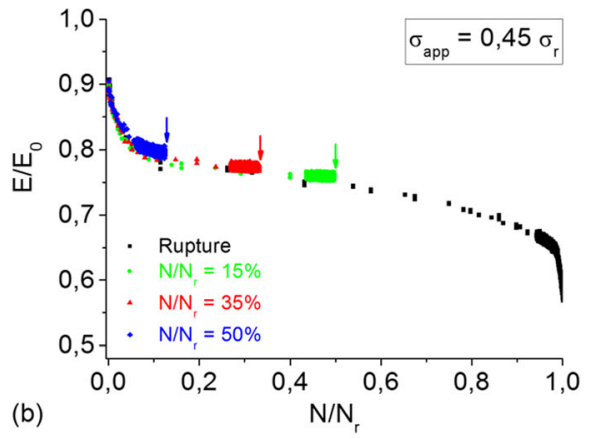

(b)

$r$

Fig. 8 Evolutions of the relative Young's modulus for different applied stresses and certain defined cycles; (a) $0.38 \sigma_{\mathrm{r}},(\mathbf{b}) 0.45 \sigma_{\mathrm{r}}$ and $(\mathbf{c}) 0.55 \sigma_{\mathrm{r}}$

specimens can also be submitted to tensile tests performed at different strain rates. Thus, damage thresholds values can be plotted as a function of strain rate (first non-linearity). Therefore, a post-fatigue damage threshold-strain rate curve can be defined for the considered damaged state $\mathrm{E} / \mathrm{E}_{0}$ ). The methodology proposed in this study consists in comparing the obtained post-fatigue curve to a reference curve established using virgin specimens (i.e. not submitted to cyclic loading) obtained for the same damaged state $\mathrm{E} / \mathrm{E}_{0}$ ) as described in paragraph 3.4.2. This comparison should emphasize the effect of fatigue loading on the residual dynamic behavior. These iso-damage-strain rate evolution curves obtained from post-fatigue dynamic tests can be established on different $\mathrm{E} / \mathrm{E}_{0}$ damage states corresponding to different values of the lifetime fraction, $\mathrm{N} / \mathrm{N}_{\mathrm{r}}$. The remaining mechanical potential of a fatigue pre-damaged sample is then compared to the virgin monotonic tension response obtained at different strain rates.

For a given damaged state, the gap observed between the post-fatigue and the virgin monotonic tensile damage threshold stresses will be attributed to specific phenomena developed in fatigue. The deviation observed on the damage threshold may be calculated for different conditions (Amplitude, $\mathrm{N} / \mathrm{N}_{\mathrm{r}}$ (or $\mathrm{E} / \mathrm{E}_{0}$ ), $\dot{\varepsilon}$ ) by the following expression:

$$
\delta_{\sigma_{\text {threshold }}}=\frac{\sigma_{\text {threshold }}^{\text {reference }}-\sigma_{\text {threshold }}^{\text {post-fatigue }}}{\sigma_{\text {threshold }}^{\text {reference }}}
$$

This parameter emphasizes the effect of the type of applied loading on the local structural state in spite of equivalent macroscopic damage states (E). Indeed, at the local scale, repeated 
loading may locally modify the strength of the different phases and leads to the significant evolution of the macroscopic mechanical response. Therefore, residual macroscopic stiffness may be not enough representative of the damage state. Indirectly, the practical issue that is springing out of this approach concerns the local effect of fatigue loading on the remaining potential at different loading strain rates.

\subsubsection{Experimental Campaign}

The selected variability parameters will be the fatigue lifetime fraction $\mathrm{N} / \mathrm{N}_{\mathrm{r}}$ which is directly related to the fatigue damage state characterized by the progressive decrease of the relative stiffness $\mathrm{E} / \mathrm{E}_{0}$ (Fig. 8). In fatigue the second parameter is the applied amplitude. Three values of applied stress were defined: $0.38 \sigma_{\mathrm{r}}, 0.45 \sigma_{\mathrm{r}}$ and $0.55 \sigma_{\mathrm{r}}\left(\sigma_{\mathrm{r}}\right.$ : ultimate stress obtained for quasi-static tensile tests defined as a reference). The fatigue tests were interrupted at different values of the lifetime fraction, $\mathrm{N} / \mathrm{N}_{\mathrm{r}}$, i.e. around $3 \%, 15 \%, 35 \%$ and $50 \%$ according to Table 2.

The correct repeatability of the interrupted fatigue tests is checked on the curves of decrease of relative stiffness (Fig. 8).

Following the interruption of the fatigue test (Fig. 8), monotonic tensile tests are carried out for three strain rates: $10^{-3} \mathrm{~s}^{-1}, 1 \mathrm{~s}^{-1}$ and, $60 \mathrm{~s}^{-1}$. Table 2 summarizes the whole experimental campaign. For each of the test conditions of this procedure (Amplitude, $\mathrm{N} / \mathrm{N}_{\mathrm{r}}\left(\right.$ or $\left.\mathrm{E} / \mathrm{E}_{0}\right), \varepsilon$ ), the tests were repeated four times. All the tests were carried out on the optimized sample geometry (Fig. 2) in order to ensure a good quality of the dynamic tests [3].

\subsubsection{Thermal and Damage Effects}

A previous study has emphasized the influence of amplitude and frequency on self-heating phenomenon developed by A-SMC composites during fatigue [25]. In order to reproduce the real conditions of use in automobile structures, fatigue tests were carried out at a frequency of $30 \mathrm{~Hz}$. At this frequency, the effect of self-heating should not be neglected. In Fig. 9, the changes in the temperature increase measured during the fatigue tests were reported for applied stresses of $0.38 \sigma_{\mathrm{r}}, 0.45 \sigma_{\mathrm{r}}$, and $0.55 \sigma_{\mathrm{r}}$.

A temperature which can exceed $50{ }^{\circ} \mathrm{C}$ is noted. However, DMTA analysis (Fig. 4) shows a significant modulus variation in this temperature range. It should be noticed that the applied strain amplitude in the DMTA test is extremely low and are not sufficient to produce selfheating. Therefore, part of the observed decrease in stiffness measured in Fig. 8 is linked to the

Table 2 Loading parameters in trials for the study of coupling fatigue-dynamic

\begin{tabular}{|c|c|c|c|c|c|}
\hline \multicolumn{3}{|l|}{ Fatigue test } & \multicolumn{3}{|l|}{ Tensile test } \\
\hline \multirow{4}{*}{$\begin{array}{l}\text { Applied stress } \\
0.38 \sigma_{\mathrm{r}}\end{array}$} & Defined cycles & $\mathrm{N} / \mathrm{N}_{\mathrm{r}}(\%)$ & \multirow{4}{*}{$\begin{array}{l}\text { Strain rate } \\
\text { quasi-static }\end{array}$} & \multirow{4}{*}{$1 \mathrm{~s}^{-1}$} & \multirow{4}{*}{$60 \mathrm{~s}^{-1}$} \\
\hline & 100,000 & 3 & & & \\
\hline & 500,000 & 15 & & & \\
\hline & $1,000,000$ & 35 & & & \\
\hline \multirow[t]{3}{*}{$0.45 \sigma_{\mathrm{r}}$} & 15,000 & 15 & \multirow[t]{3}{*}{ quasi-static } & \multirow[t]{3}{*}{$1 \mathrm{~s}^{-1}$} & \multirow[t]{3}{*}{$60 \mathrm{~s}^{-1}$} \\
\hline & 40,000 & 35 & & & \\
\hline & 60,000 & 50 & & & \\
\hline \multirow[t]{2}{*}{$0.55 \sigma_{\mathrm{r}}$} & 1000 & 15 & \multirow[t]{2}{*}{ quasi-static } & \multirow[t]{2}{*}{$1 \mathrm{~s}^{-1}$} & \multirow[t]{2}{*}{$60 \mathrm{~s}^{-1}$} \\
\hline & 2500 & 35 & & & \\
\hline
\end{tabular}




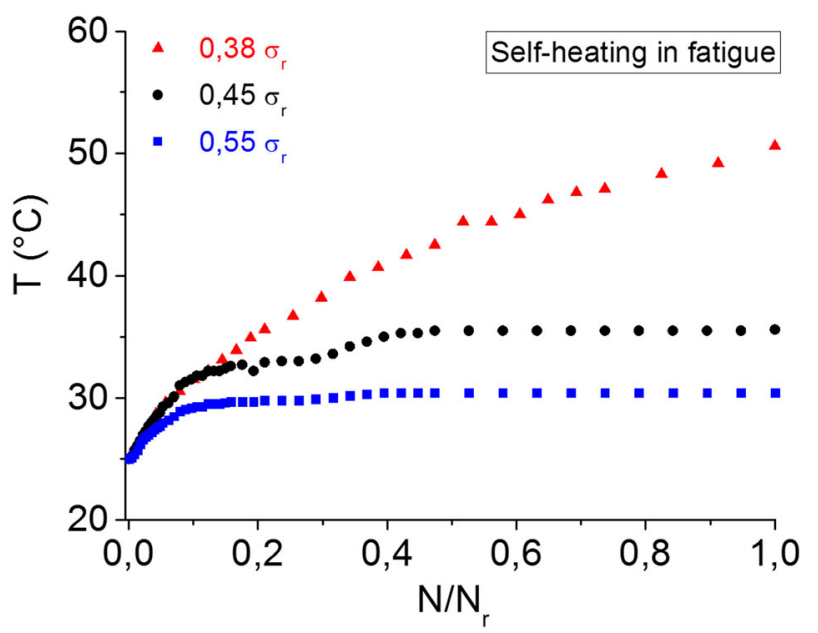

Fig. 9 Temperature variation during fatigue tests at different amplitudes $(\mathrm{f}=30 \mathrm{~Hz})$

self-heating phenomenon. Our approach is based on the analysis of the stiffness decrease due to damage, thus we must extract the evolution of the relative modulus due to the temperature increase in the range from $25^{\circ} \mathrm{C}$ to $75^{\circ} \mathrm{C}$ which corresponds to the zone of the transition $\beta$ (around $45^{\circ} \mathrm{C}$ ). To this aim, Figs. 4 and 9 should be used in order to extract the loss of stiffness due to thermal part induced by the self-heating, $(\mathrm{E} / \mathrm{E} 0)_{\mathrm{T}}$ by considering the following relation:

$$
\frac{E}{E_{0}}=1-\left(\frac{E}{E_{0}}\right)_{T}-\left(\frac{E}{E_{0}}\right)_{D}
$$

Where $\left(\frac{E}{E_{0}}\right)_{D}$ corresponds to the stiffness decrease due to damage only. This treatment is illustrated in the case of the amplitudes of $0.38 \sigma_{\mathrm{r}}, 0.45 \sigma_{\mathrm{r}}$ and $0.55 \sigma_{\mathrm{r}}$ on the curves of Fig. 10. It should be noted that for this frequency, the thermal part remains relatively limited except for the amplitude of $0.55 \sigma_{\mathrm{r}}$.

Therefore, all the following analysis exclusively considers the stiffness reduction due to damage.

\subsection{Post-Fatigue Dynamic Tensile Behavior}

Tensile tests at different strain rates (from QS to $60 \mathrm{~s}^{-1}$ ) were performed on several pre-damaged RO-A-SMC samples. Three applied amplitudes values were chosen: $0.38 \sigma_{\mathrm{r}}, 0.45 \sigma_{\mathrm{r}}$ and, $0.55 \sigma_{\mathrm{r}}$, according to the protocol presented in Table 2. Postfatigue stress-strain curves $(\sigma-\varepsilon)$ at different applied strain rates are plotted in Fig. 11 for different applied strain rates and fatigue lifetime fraction values $\left(\mathrm{N} / \mathrm{N}_{\mathrm{r}}\right)$. In this example, applied fatigue amplitudes were of $0.38 \sigma_{\mathrm{r}}$. Independently of the applied strain rate, one can observe that the residual Young's modulus decreases when the applied lifetime fraction increases. The normalized stress (respectively strain) corresponds to the ratio between the measured stress (respectively strain) and the ultimate stress (respectively strain) obtained for a quasi-static tensile test chosen as a reference. 

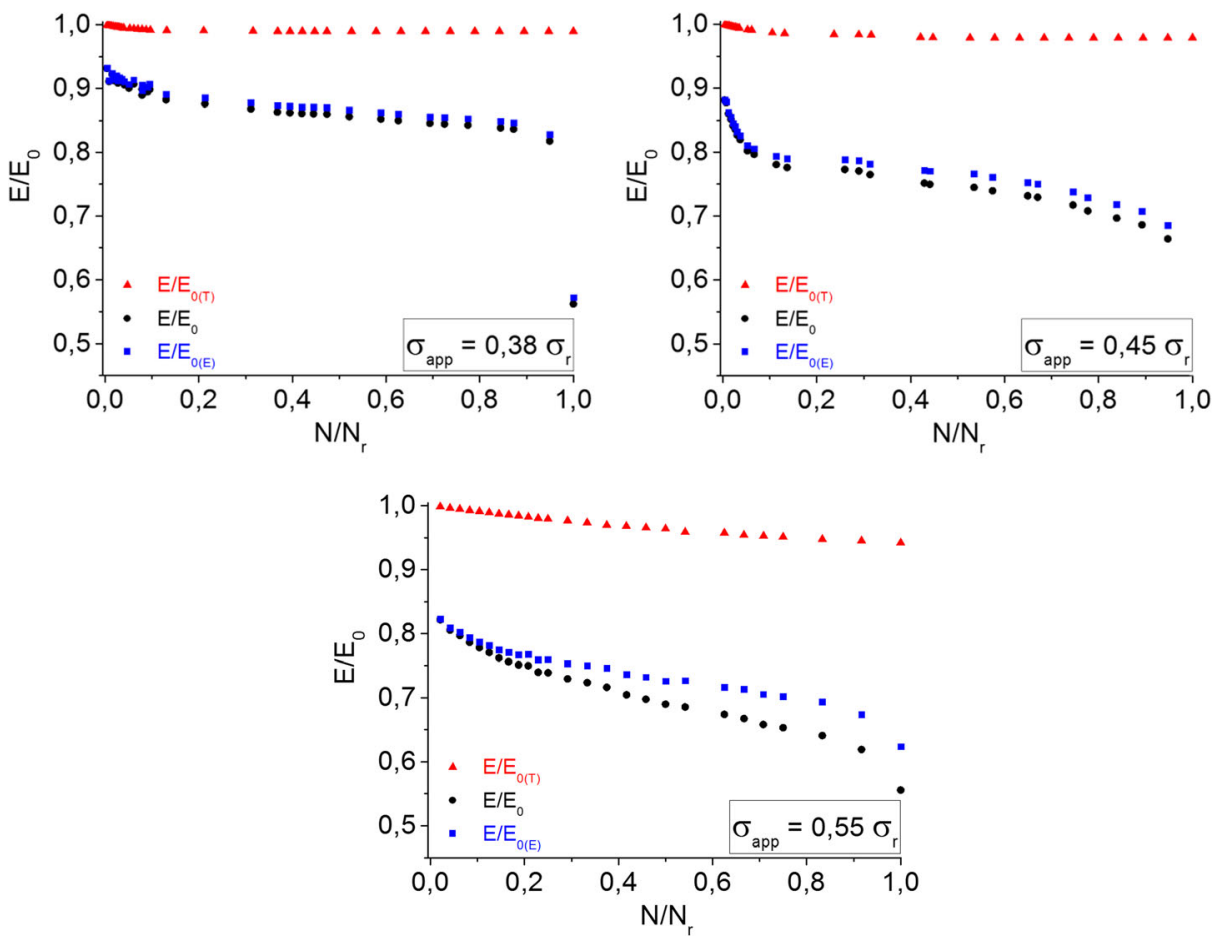

Fig. 10 Decomposition on the thermal part and on the part related to the damage; (a) $0.38 \sigma_{\mathrm{r}},(\mathbf{b}) 0.45 \sigma_{\mathrm{r}}$ and (c) $0.55 \sigma_{\mathrm{r}}$

\subsection{Strain Rate Effect on Fatigue Pre-Damaged A-SMC}

\subsubsection{Residual Stiffness}

In a previous study [3], it has been shown that the strain rate effect on A-SMC elastic behavior is negligible. Therefore, in order to get good precision on the post-fatigue damage state prior to all dynamic tensile stage, the elastic modulus (initial slopes of the stress-strain curves) was measured by quasi-static tensile test until $50 \%$ of the maximum applied stress during the fatigue stage. Figure 12 shows the evolution of $\mathrm{E} / \mathrm{E}_{0}$ for pre-damaged A-SMC obtained from the dynamic tensile test as a function of strain rate for different fatigue loading conditions and lifetime fractions. As expected, the residual Young's modulus decreases when increasing the applied fatigue lifetime fraction. However, even after the fatigue tests, the strain rate effect remains negligible similarly to the virgin material. One can observe that the stiffness variation with the applied fatigue lifetime is of the same magnitude for all the applied fatigue amplitude. Therefore, one can conclude that the local repeated deformations during fatigue tests do not affect the macroscopic stiffness.

\subsubsection{Threshold and Ultimate Characteristics}

Post-fatigue material characteristics, namely damage thresholds corresponding to the first nonlinearity $\left(\sigma_{\text {threshold }} ; \varepsilon_{\text {threshold }}\right)$ and ultimate stress and strain $\left(\sigma_{\text {ultimate }} ; \varepsilon_{\text {ultimate }}\right)$, are plotted as a 

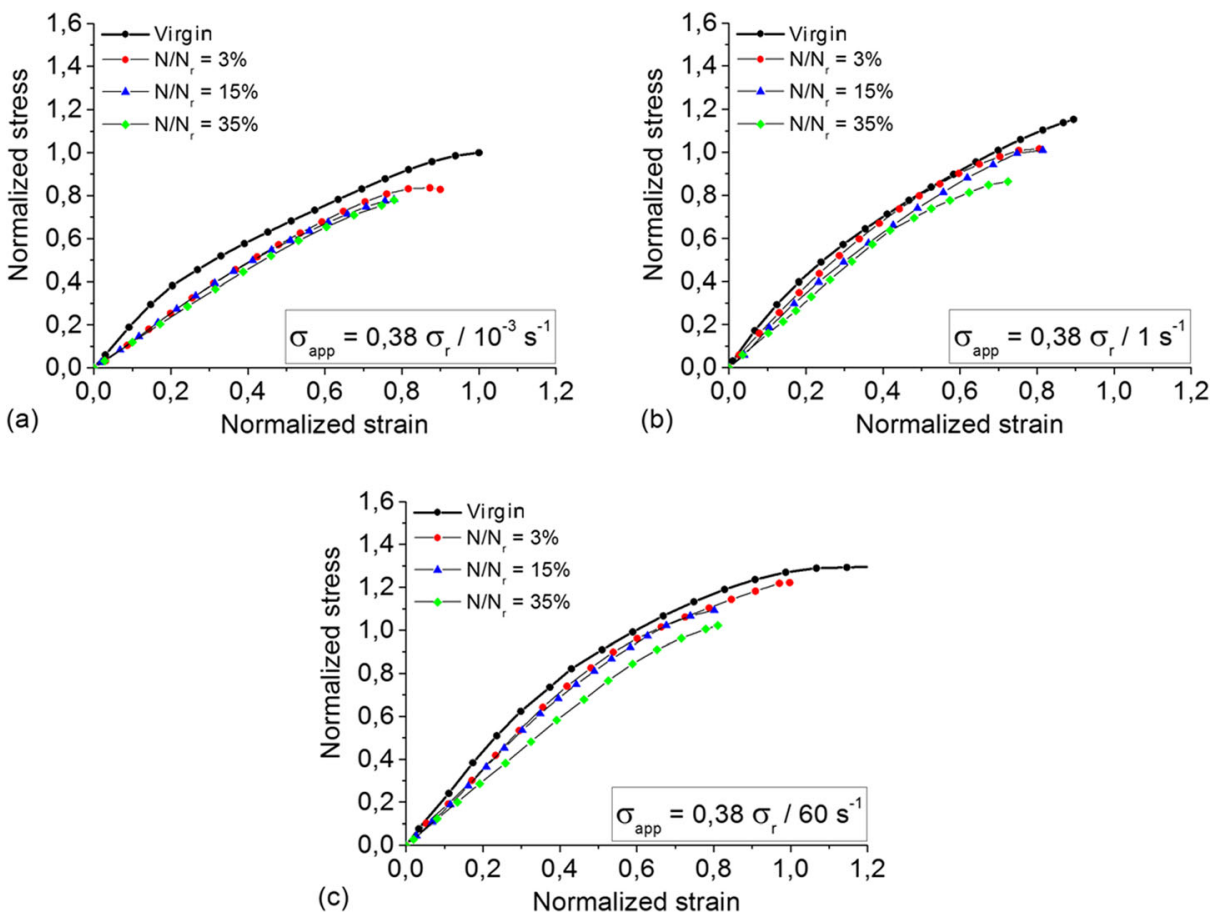

Fig. 11 Experimental tensile curves obtained at variable strain rate on specimens submitted to fatigue applied stress of $0.38 \sigma_{\mathrm{r}}$ for different lifetime fraction $\left(\mathrm{N} / \mathrm{N}_{\mathrm{r}}\right)$ : (a) quasi-static, (b) $1 \mathrm{~s}^{-1}$ and (c) $60 \mathrm{~s}^{-1}$

function of strain rate in Fig. 13. Normalized characteristic is defined to be the ratio between the considered characteristic under post-fatigue tensile loading and ultimate quasi-static characteristic. Indeed, the quasi-static tensile response was defined as a reference. Note that the ultimate characteristics correspond to the maximum stress (or strain) level (before delamination when it occurs, see [3] for more description). The non-linear overall response of both non-damaged and fatigue pre-damage A-SMCs composites are drastically influenced by the strain rate.

One can note the particularly high strain rate dependence of the damage threshold independently of the loading conditions. More than $100 \%$ variation of the threshold stress and strain can be observed.

One can notice that for all tests, no significant strain rate effect is noticed on the ultimate strain.

\subsection{Analysis}

\subsubsection{Evolution of the Relative Ultimate Properties}

As mentioned, based on the curves of Fig. 11, it is observed that the fatigue pre-damaged samples present a remaining monotonic mechanical potential always lower than the virgin samples. For example, the results are shown in Fig. 13(c) shows a decrease of the residual ultimate stress of about $50 \%$ relative to the virgin samples which this decrease is independent of the strain rate. Indeed, the curves remain parallel and their level is the only function of the lifetime fraction (or in other words of the reached damage level). 

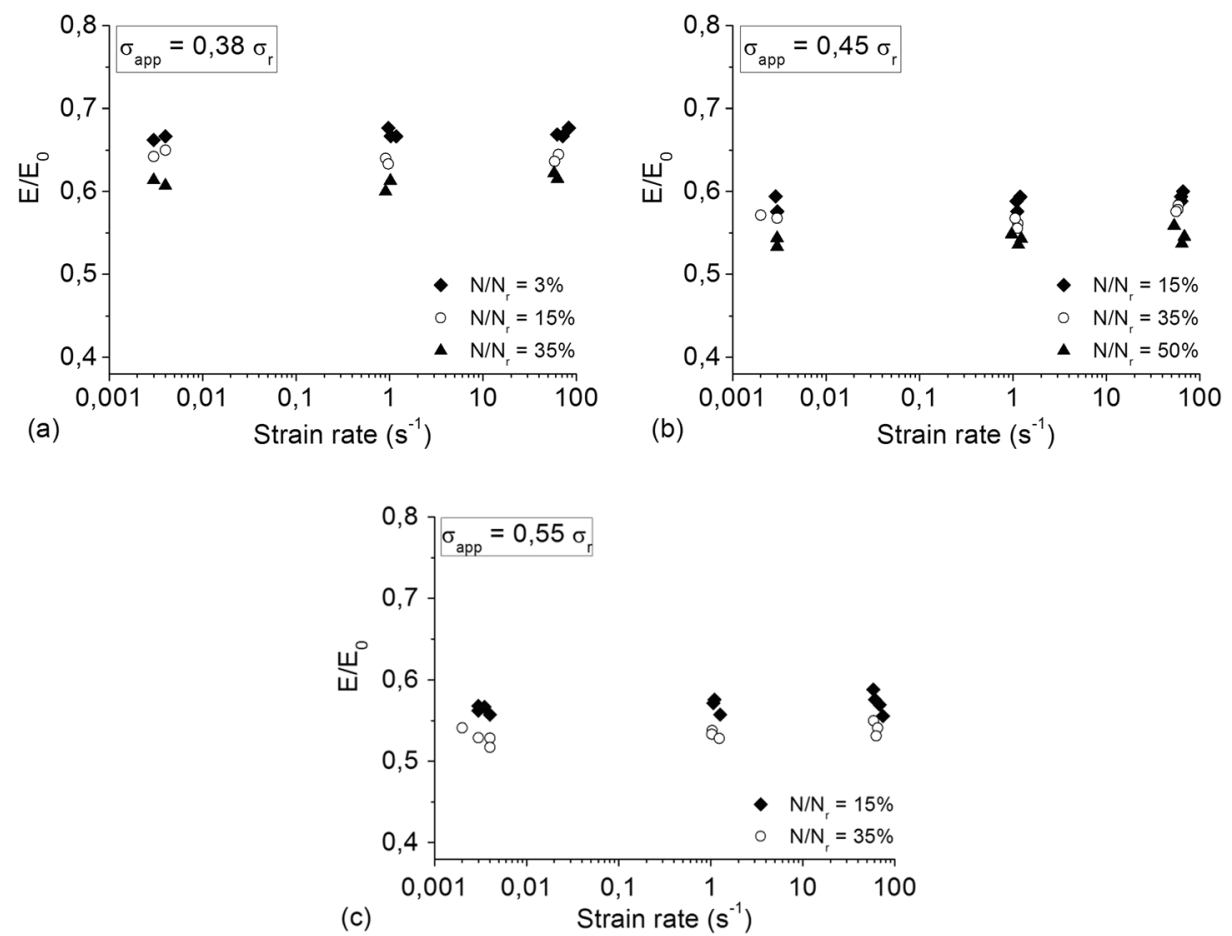

Fig. 12 Influence of strain rate on the elastic modulus: (a) $\sigma_{\text {app }}=0.38 \sigma_{\mathrm{r}}$, (b) $\sigma_{\text {app }}=0.45 \sigma_{\mathrm{r}}$, (c) $\sigma_{\text {app }}=0.55 \sigma_{\mathrm{r}}$

Therefore, we can plot the evolution of the relative ultimate stress defined by the ratio: $\frac{\sigma^{\mathrm{r}}(\varepsilon)}{\sigma_{\mathrm{QS}}^{\mathrm{r}}}$ where $\sigma_{\mathrm{QS}}^{\mathrm{r}}$ is the average ultimate stress under quasi-static loading and $\sigma^{\mathrm{r}}(\dot{\varepsilon})$ is the ultimate stress for an applied strain rate $\dot{\varepsilon}$. Then Fig. 13(c) is converted to Fig. 14 which indicates a single evolution as a function of the strain rate not depending on the cyclic loading amplitude and the imposed fatigue damage state (represented here by the lifetime fraction). Consequently, one can conclude that the damage level reached by fatigue do not impact significantly the strain rate sensitivity. In other words, the local phenomena which lead to failure under dynamic loading are not affected by local microscopic modifications induced by cyclic loading.

\subsubsection{Analysis of the Threshold Deviation Parameter Evolutions}

As it was presented in paragraph 3.4.3, one can study the effect of a fatigue pre-damage on the residual dynamic properties by comparison to that obtained on a reference equivalent damaged state generated by monotonic loading. As it is described in Table 2, several interrupted fatigue tests have been performed in order to generate different levels of fatigue damage. Contrary to Table 2 , here, the latter is characterized by the macroscopic damage parameter D classically defined by $\mathrm{D}=1-\mathrm{E} / \mathrm{E}_{0}[26]$.

Therefore, for each reached value of $\mathrm{D}$, the evolution of the threshold stress versus strain rate can be determined experimentally. The deviation parameter defined in eq. (9) can then be calculated and plotted as a function of the cyclic pre-damage D and the strain rate $\varepsilon$ (see Fig. 15). 

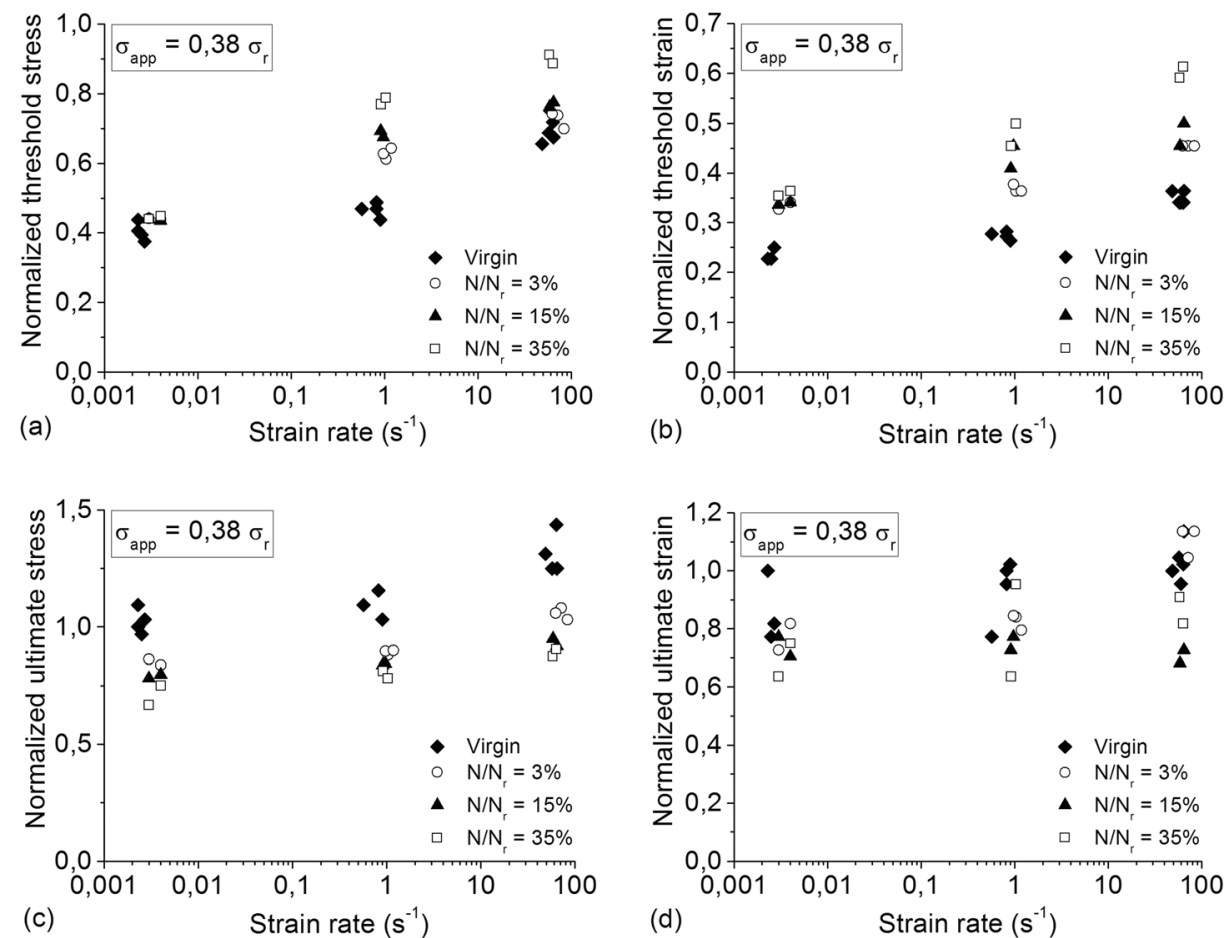

Strain rate $\left(\mathrm{s}^{-1}\right)$

Fig. 13 Influence of strain rate on: (a) Normalized threshold stress, (b) Normalized threshold strain, (c) Normalized ultimate stress and (d) Normalized ultimate strain; $\left(\sigma_{\mathrm{app}}=0.38 \sigma_{\mathrm{r}}\right)$

It was stated that the origin of the observed gap between post-fatigue curves and those of post-monotonic ones is attributed to specific phenomena developed in fatigue at the local scale.

The quasi-static response of specimens submitted to a pre-damage by fatigue can be considered as equivalent to those of specimens pre-damaged by monotonic loading. Indeed, for quasi-static loading, the deviation parameter is always negligible. On the other hand, at

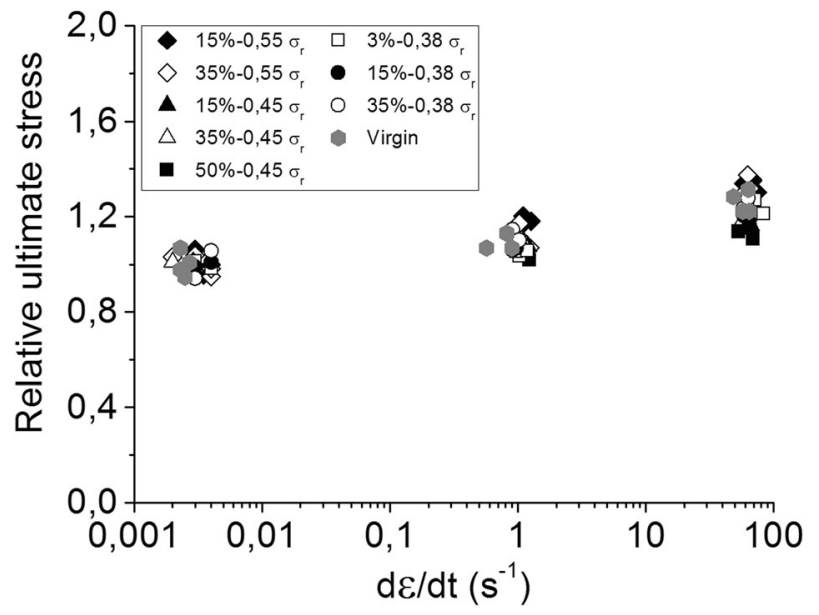

Fig. 14 Relative value of the ultimate stress for different values of the imposed amplitudes and the lifetime fractions 


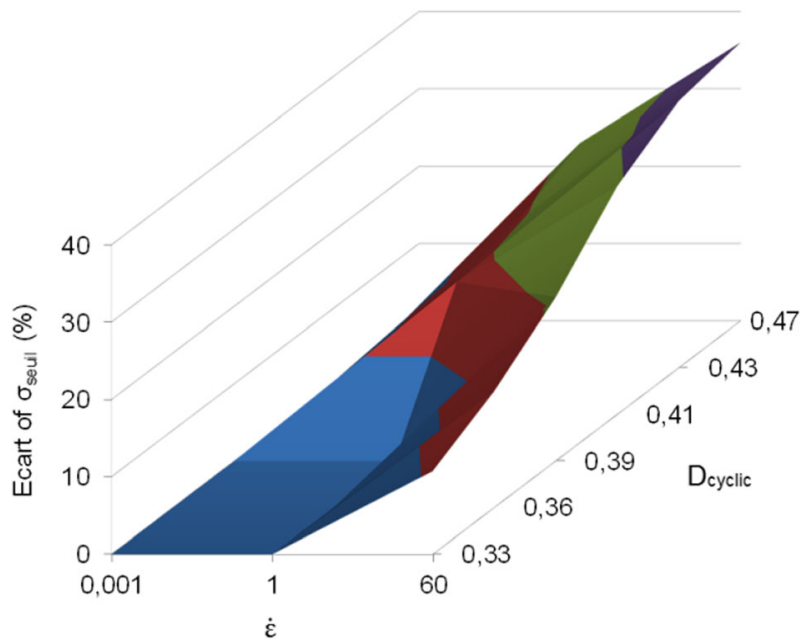

Fig. 15 Evolution of the gap between the measured post-fatigue properties and that of reference at different strain rates and damage states

higher strain rates, the deviation parameter increases when the fatigue pre-damage level increases. This suggests that local repeated deformations lead to the embrittlement of the fiber-matrix interfaces, especially at high strain rate. Indeed, one can also notice that when the degree of damage applied under fatigue conditions increases, sensitivity to strain rate increases (see Fig. 15). Therefore, one can conclude that the fiber-matrix interface weakening is more marked when applying cyclic mechanical conditions. Moreover, this effect is enhanced for increasing strain rates.

\section{Conclusion}

The methodology proposed in this paper consists in comparing the iso-damage evolution curves (modulus E) obtained from post-fatigue dynamic tests to those which can be obtained in monotonic dynamic traction. The comparison has been made on successive equivalent $\mathrm{E}$ damage states corresponding to different values of the lifetime fraction, $\mathrm{N} / \mathrm{N}_{\mathrm{r}}$. The remaining potential of a pre-damaged sample is then compared with the pre-damaged monotonic tension at different strain rates. The differences observed between the post-fatigue and the monotonic tensile evolutions will be attributed to the specific phenomena developed in fatigue. Tensile results of pre-damaged A-SMCs showed the elastic modulus remains insensitive to strain rate. The fatigue pre-damaged samples presented a remaining monotonic mechanical potential always lower than the virgin samples. This decrease is independent of the strain rate. Indeed, the curves remain parallel and their level is the only function of the lifetime fraction (or in other words of the reached damage level). The quasi-static response of specimens submitted to a predamage by fatigue can be considered as equivalent to those of specimens pre-damaged by monotonic loading. Indeed, for quasi-static loading, the deviation parameter was always negligible. On the other hand, at higher strain rates, the deviation parameter increases when the fatigue pre-damage level increases. This suggests that local repeated deformations lead to the embrittlement of the fiber-matrix interfaces, especially at high strain rate. Indeed, one can also notice that when the degree of damage applied under fatigue conditions increases, 
sensitivity to strain rate increases. Therefore, one can conclude that the fiber-matrix interface weakening is more marked when applying cyclic mechanical conditions. Moreover, this effect is enhanced for increasing strain rates.

\section{References}

1. Thornton, P.H., Edwards, P.J.: Energy absorption in composite tubes. J. Compos. Mater. 16(6), 521-545 (1982)

2. Uenishi, A., Kuriyama, Y., Yoshida, H., Takahashi, M.: Material characterization at high strain rates for optimizing Car body structures for crash events. Nippon Steel Technical Report. 378(88), 21 (2003)

3. Obradovic, J., Boria, S., Belingardi, G.: Lightweight design and crash analysis of composite frontal impact energy absorbing structures. Compos. Struct. 94(2), 423-430 (2012)

4. Alia, R.A., Cantwell, W.J., Langdon, G.S., Yuen, S.C.K., Nurick, G.N.: The energy-absorbing characteristics of composite tube-reinforced foam structures. Compos. Part B. 61, 127-135 (2014)

5. Tang, H., Chen, Z., Zhou, G., Sun, X., Li, Y., Huang, L., Guo, H., Kang, H., Zeng, D., Engler-Pinto, C., Su, $\mathrm{X}$.: Effect of fiber orientation distribution on constant fatigue life diagram of chopped carbon fiber chipreinforced sheet molding compound (SMC) composite. Int. J. Fatigue. 125, 394-405 (2019)

6. Guster, C., Pinter, G., Mosenbacher, A., Eichlseder, W.: Evaluation of a simulation process for fatigue life calculation of short fibre reinforced plastic components. Proc. Eng. 10(0), 2104-2109 (2011)

7. Nony-Davadie, C., Peltier, L., Chemisky, Y., Surowiec, B., Meraghni, F.: Mechanical characterization of anisotropy on a carbon fiber sheet molding compound composite under quasi-static and fatigue loading. J. Compos. Mater. 53(11), 1437-1457 (2019)

8. Mortazavian, S., Fatemi, A.: Fatigue behavior and modeling of short fiber reinforced polymer composites including anisotropy and temperature effects. Int. J. Fatigue. 77, 12-27 (2015)

9. Atodrais, D.R., Putatundaa, S.K., Mallick, P.K.: Fatigue crack growth model and mechanism of a random fiber SMC composite. Polym. Compos. 20(2), 240-249 (1999)

10. Bellenger, V., Tcharkhtchi, A., Castaing, P.: Thermal and mechanical fatigue of a PA66/glass fibers composite material. Int. J. Fatigue. 28(10), 1348-1352 (2006)

11. Esmaeillou, B., Ferreira, P., Bellenger, V., Tcharkhtchi, A.: Fatigue behavior of polyamide 66/glass fiber under various kinds of applied load. Polym. Compos. 33(4), 540-547 (2012)

12. Esmaeillou, B., Fitoussi, J., Lucas, A., Tcharkhtchi, A.: Multi-scale experimental analysis of the tensiontension fatigue behavior of a short glass fiber reinforced polyamide composite. Proc. Eng. 10(0), 2117-2122 (2011)

13. Shirinbayan, M., Fitoussi, J., Meraghni, F., Surowiec, B., Bocquet, M., Tcharkhtchi, A.: High strain rate visco-damageable behavior of advanced sheet molding compound (A-SMC) under tension. Compos. Part B. 3670(82), 30-41 (2015)

14. Fitoussi, J., Guo, G., Baptiste, D.: A statistical micromechanical model of anisotropic damage for S.M.C. composites. Compos. Sci. Technol. 58(5), 759-763 (1998)

15. Fitoussi, J., Bocquet, M., Meraghni, F.: Effect of the matrix behavior on the damage of ethylene-propylene glass fiber reinforced composite subjected to high strain rate tension. Compos. Part B. 45(1), 1181-1191 (2013)

16. Fitoussi, J., Meraghni, F., Jendli, Z., Hug, G., Baptiste, D.: Experimental methodology for high strain-rates tensile behaviour analysis of polymer matrix composites. Compos. Sci. Technol. 65(14), 2174-2188 (2005)

17. Jendli, Z., Meraghni, F., Fitoussi, J., Baptiste, D.: Micromechanical analysis of strain rate effect on damage evolution in sheet molding compound composites. Compos. A: Appl. Sci. Manuf. 35(7-8), 779-785 (2004)

18. Jendli, Z., Fitoussi, J., Meraghni, F., Baptiste, D.: Anisotropic strain rate effects on the fibre-matrix interface decohesion in sheet moulding compound composites. Compos. Sci. Technol. 65(3-4), 387-393 (2005)

19. Jia, W.P., Fernandes, J.V.: Mechanical behaviour and the evolution of the dislocation structure of copper polycrystal deformed under fatigue-tension and tension-fatigue sequential strain paths. Mater. Sci. Eng. A. 348(1-2), 133-144 (2003)

20. Ray, D., Sarkar, B.K., Bose, N.R.: Impact fatigue behaviour of vinylester resin matrix composites reinforced with alkali treated jute fibres. Compos. A: Appl. Sci. Manuf. 33(02), 233-241 (2002)

21. Epaarachchi, J.: Effects of static-fatigue (tension) on the tension-tension fatigue life of glass fibre reinforced plastic composites. Compos. Struct. 74(04), 419-425 (2005)

22. Le, T.H., Dumont, P.J.J., Orgéas, L., Favier, D., Salvo, L., Boller, E.: X-ray phase contrast microtomography for the analysis of the fibrous microstructure of SMC composites. Compos. A: Appl. Sci. Manuf. 39(1), 91103 (2008) 
23. Palmer, J., Savage, L., Ghita, O.R., Evans, K.E.: Sheet moulding compound (SMC) from carbon fibre recyclate. Compos. A: Appl. Sci. Manuf. 41(9), 1232-1237 (2010)

24. Garcea, S.C., Wang, Y., Withers, P.J.: X-ray computed tomography of polymer composites. Compos. Sci. Technol. 156, 305-319 (2018)

25. M. Shirinbayan, J. Fitoussi, F. Meraghni, M. Laribi, B. Surowiec, A. Tcharkhtchi. Coupled effect of loading frequency and amplitude on the fatigue behavior of advanced sheet molding compound (A-SMC). J. Reinf. Plast. Compos. 2017;36(4): 271-282

26. Laribi, M.A., Tamboura, S., Fitoussi, J., Tcharkhtchi, A., Ben Dali, H.: Fast fatigue life prediction of short fiber reinforced composites using a new hybrid damage approach: application to SMC. Compos. Part B. 139, 155-162 (2018)

27. Shirinbayan, M., Fitoussi, J., Bocquet, M., Meraghni, F., Surowiec, B., Tcharkhtchi, A.: Multi-scale experimental investigation of the viscous nature of damage in advanced sheet molding compound (ASMC) submitted to high strain rates. Compos. Part B. 115, 3-17 (2017)

Publisher's Note Springer Nature remains neutral with regard to jurisdictional claims in published maps and institutional affiliations.

\title{
Affiliations
}

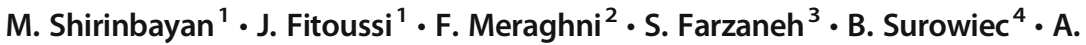 Tcharkhtchi $^{1}$}

\author{
Arts et Métiers ParisTech, PIMM - UMR CNRS 8006, 151 Boulevard de l'Hôpital, 75013 Paris, France \\ 2 Arts et Métiers ParisTech, LEM3 - UMR CNRS 7239, 4 Rue Augustin Fresnel, 57078 Metz, France \\ 3 P4 Tech, 94 rue Léon Geffroy, 94440, Vitry Sur Seine, France \\ 4 Plastic Omnium Auto Exterior, Sigmatech, Sainte Julie, France
}

